\title{
Temporal Evolution of Clear-Water Local Scour at Bridge Piers with Flow-Dependent Debris Accumulations
}

\author{
Francisco Nicolás Cantero-Chinchilla1; Gustavo Adolfo Mazza de Almeida²; and \\ Costantino Manes ${ }^{3}$
}

\begin{abstract}
Previous research has shown that local scour at bridge piers is severely increased by the accumulation of woody debris around piers. However, due to the unavailability of accurate information regarding the characteristics of formed debris jams, the shape and dimensions of accumulations tested in previous laboratory experiments had to be assumed. This article provides an assessment of debris-induced scour based on recently available knowledge about the relation between the potential dimensions of debris accumulations, the characteristics of flow and debris elements. Clear-water scour experiments (with and without debris accumulation) were conducted using debris models with shape and size that correspond to the particular flow characteristics of each experiment. The results showed that scour depths obtained with flow-dependent debris accumulations were larger than without accumulations by a factor ranging from 1.18-2.19. The analysis of the scour depths affected by the accumulations suggested similarity characteristics as well as dependence on the flow intensity, blockage area ratio and depth ratio.
\end{abstract}

Author keywords: Woody-debris; Bridge pier; Bridge scour; Temporal scour evolution.

\footnotetext{
${ }^{1}$ Research Fellow, Soil and Water division, IAS-CSIC, Spanish National Research Council, Alameda del Obispo s/n, 14004 Córdoba, Spain. E-mail: z12cachf@uco.es (corresponding author).

${ }^{2}$ Lecturer, Water Engineering and Environmental group, University of Southampton, SO17 1BJ, UK. E-mail: G.deAlmeida@soton.ac.uk

${ }^{3}$ Associate Professor, Department of Environment, Land and Infrastructure Engineering, Politecnico di Torino, Corso Duca degli Abruzzi, 24, 10129 Torino, Italy. E-mail: costantino.manes@,polito.it
} 


\section{Introduction}

21 During flood events in river basins characterized by large wooded lands, floating woody debris may accumulate at the pier front leading to further alterations of the flow velocity, turbulence and pier loadings (Diehl 1997; Parola et al. 2000; Bradley et al. 2005; Lagasse et al. 2010). Investigations on the potential cause of bridge failures indicate that debris contributes to approximately one-third of all failures of fluvial bridges in the US, UK and Ireland (Diehl 1997; Benn 2013).

The effect of large woody debris (LWD) accumulations on bridge pier scour has been studied over the past decades by means of simplified laboratory models of debris jams (Melville and Dongol 1992; Pagliara et al. 2010; Pagliara and Carnacina 2013; Najafzadeh et al. 2017; Rahimi et al. 2017) having impermeable, cylindrical or prismatic shapes (Melville and Dongol 1992; Pagliara and Carnacina 2010a; Rahimi et al. 2017). However, the shape of LWD accumulations observed in the real-world is far from prismatic and solid, nor is it independent on the flow conditions, channel geometry and the characteristics of the transported debris (Melville and Coleman 2000; Schmocker and Hager 2013). Only a few works have been conducted using models with a shape, porosity and roughness that resemble the characteristics of accumulations formed in rivers (Laursen and Toch 1956; Lagasse et al. 2010) even though the dimensions of the debris jams used, which has an important effect on scour (Pagliara and Carnacina 2011, 2013), had to be assumed. Recently, Panici and de Almeida (2017, 2018, 2020) defined empirical relations between the maximum dimensions of debris jams (made of rigid elements) and the characteristics of flow and debris elements for single, isolated piers under steady flow and a constant supply of debris over a fixed bed (clear-water conditions). That investigation found that the maximum dimensions and shape of jams that are likely to be formed by a natural process of self-assembly of individual pieces can be accurately modelled as inverted half-cones defined by three reference lengths $(H, W, K$, as shown in Fig. 1a, which are the submerged height, width, and length of the debris accumulation, respectively) as follows:

$$
D_{i}=A_{i}+B_{i} \exp \left[-C_{i} \mathrm{Fr}_{L}\right] \text {, }
$$

where $\mathbf{D}=\left[W / l_{\log }, H / l_{\log }, K / l_{\log }\right] ; \mathbf{A}=[0.99,0.7,0.47] ; \mathbf{B}=[3.24,-0.89,3.72] ; \mathbf{C}=[4.63,3,9.94]$; and $\mathrm{Fr}_{L}=\log$ Froude number $\left[=U /\left(g l_{l o g}\right)^{1 / 2}\right]$, where $U=$ depth-averaged streamwise velocity; $g=$ gravitational acceleration; and $l_{l o g}=$ longest length of logs within the accumulation (which for 
accumulations made of uniform length logs coincides with the constant length). The subscript $i$ $(=1,2,3)$ is used to denote the component of the vectors. Even though live-bed conditions often prevail in pier scour, Eq. (1) was originally developed under fixed bed conditions as a first attempt to model the debris accumulation formation and, to that purpose, it is adopted in this study. Implicit to this approach is the assumption that the presence of the scour hole has a negligible influence on the formation of debris accumulations, which is primarily governed by the advection of floating debris by the near free-surface flow. Although experiments under a constant debris supply showed that debris accumulations build up gradually (Panici and de Almeida, 2018), the evolution of accumulations in rivers is unpredictable due to the randomness of debris transport. For this reason, Eq. (1) is used here to define the dimensions of debris models corresponding to the critical condition observed in Panici and de Almeida (2018) (i.e. maximum dimensions). This condition is assumed to represent the worst-case scenario, whereby the flow obstruction produces the maximum effect on scour.

The present technical note reports results from three sets of experiments, the rationale of which introduces the objectives of the study. The first set consists of 34 local scour experiments that were conducted with and without the twigs-made debris-models resembling dimensions proposed by Panici and De Almeida (2018). This set of experiments intends to quantify the relative increase of the local scour depth and to derive a predictive equation to quantify the worsening effect of debris on scour. A second set involved three pairs of experiments using debris models with dimensions corresponding to the adopted flow and twig characteristics [i.e. defined following Eq. (1)] as well as three tests with a debris model with size different from that predicted by Eq. (1). These experiments helped assessing the potential impact of adopting arbitrary debris models on predicted scour depths. Finally, the third set involved the comparison between two experiments: one with a debris model used in the first set and another one with a replica of the same model made of impermeable foam instead of twigs. This set was conducted in order to investigate the effects of debris permeability on local scour, which was originally investigated by Lagasse et al. (2010) and Pagliara and Carnacina (2010b) however using arbitrary shapes and dimensions for the debris models.

\section{Experiments}


Consider the idealized case of an open channel flow over an erodible bed with uniform sediment diameter (and fixed density $\rho_{s}$ ) and within a rectangular channel of width $b$ and depth $h$. In such a case, Fig. 1b depicts the main flow features in pier scour affected by woody debris accumulations (Pagliara and Carnacina 2013, Dey 2014), including the expected flow diversion likely to affect scour. Debris accumulations are also known to produce energy losses leading to backwater effects, such as the afflux, the study of which is however out of the scope of this work. In order to quantify the implications of such flow alterations on local scour $\left(d_{s}\right)$, the approach proposed by Pagliara and Carnacina (2010a, 2010b) is followed. Within the context of the idealized conditions considered herein, these authors argued that the main parameters influencing the non-dimensional temporal evolution of scour $\left(d_{s} / D\right)$ are the relative depth $h / D$, the sediment coarseness $d_{50} / D$, the flow intensity $U / U_{\mathrm{c}}$ and the non-dimensional time $T=U t / D$, where $D=$ pier width; $d_{50}=$ median (50 percentile) sediment diameter; $U_{c}=$ mean critical velocity [herein estimated by Lavy's (1956) expression (Dey 2014)]; and $t=$ time. When debris effects are taken into consideration, this pool of non-dimensional parameters must be complemented with others describing the properties of the debris accumulation. Pagliara and Carnacina (2010a, 2010b) argued that such non-dimensional parameters should be obtained out of the following: a set of length scales describing the size and shape of the accumulation $L_{i}$ (in the present case, $H, W$ and $K$ ), the characteristic length scale describing the logs composing the debris $l_{\log }$, the porosity of the accumulation $n_{d}$ and a parameter accounting for the whole obstruction caused by the coupled pier-debris accumulation, which, especially within the context of laboratory experiments where flumes are of limited width, can play a significant role on scour. They called this parameter the blockage area ratio $A^{*}$, which for the debris accumulation geometries considered herein might be defined as $A^{*}=A_{b} /(h b)$, where $A_{b}=H W / 2+D(h-H)$. Pagliara and Carnacina (2010b) also argued that the parameter $T$ should be altered to account for the effective increase of the pier-size due to the presence of debris accumulations, defining a new non dimensional time as $T^{*}=h U t / A_{b}$. On top of this, it is argued in this work that the main effect of $W$ on scour is to dictate the blockage area ratio $A^{*}$ and, therefore, can be considered redundant. Moreover, while the density of debris $\rho_{L}$ may play an important role in the formation -thus on the dimensions - of debris accumulations (Panici and de Almeida 2018), is not expected to influence scour directly and, thus, it is not herein considered. In addition, Pagliara and Carnacina (2010b) and Lagasse et al. (2010), indicated that the dependency of $d_{s}$ on $n_{d}$ is minimal and 
111 hence $n_{d}$ can also be neglected. Therefore, using the pier diameter $D$ as the repeating variable, it

112 is possible to link the non-dimensional local scour with the following set of non-dimensional 113 parameters

$$
\frac{d_{s}}{D}=f\left(\frac{h}{D}, U^{*}, T^{*}, \frac{d_{50}}{D}, A^{*}, \frac{H}{h}, \frac{K}{D}, \frac{l_{l o g}}{D}\right) .
$$

Note that $H / h$ in Eq. (2) was obtained by combining $H / D$ with $h / D$. In agreement with Pagliara and Carnacina (2010b), this parameter was preferred to $H / D$ as it is more effective to quantify the acceleration of the flow occurring beneath the debris, which is presumably an important scour-worsening mechanism.

According to Oliveto and Hager $(2002,2005)$, the temporal development of the local scour without debris accumulation in clear water conditions follows the logarithmic law (Pagliara and Carnaciana 2010b)

$$
\frac{d_{s}}{D}=\varepsilon \ln \left(\frac{T^{*}}{10}\right)
$$

where $\varepsilon$ is the scour evolution rate, which can depend on all the non-dimensional parameters on the right-hand side of Eq. (2) with obvious exception of $T^{*}$. In the work presented herein $\varepsilon$ will be used to quantify and compare the severity of scour for all experimental conditions.

A set of experiments were, thus, conducted to investigate the effects on $\varepsilon$ of only those dimensionless groups in Eq. (2) related to the debris dimensions. 17 pairs of local scour experiments were carried out with and without debris accumulation for various sediment and flow conditions, but all under clear-water conditions, in a large flume at the University of Southampton. The experiments were conducted in a $23 \mathrm{~m}$ long, $1.38 \mathrm{~m}$ wide, and $0.6 \mathrm{~m}$ deep flume, while debris models were attached to a circular pier (cylinder) of $0.1 \mathrm{~m}$ diameter. A complete description of the experimental campaign is available online as supplemental material (supplemental Appendix I) in the ASCE Library (ascelibrary.org), including a sketch of the experimental setup (Fig. S1), debris model photographs (Fig. S2) and a table with characteristics of the paired experiments (Table S1). As debris models, rigid twigs were selected to resemble conditions under which Eq. (1) was originally developed by Panici and de Almeida (2018). While a comprehensive description of the influence of debris on scour would require tests under 
both clear-water and live bed conditions, in this first comparative study the focus is exclusively on the simplest scenario of clear-water scour.

\section{General Debris Effects on Local Scour}

Figs. $2 \mathrm{a}$ and $2 \mathrm{~b}$ present $d_{s} / D$ vs $T^{*}$ graphs obtained from the first set of experiments (described in the supplemental Appendix I). It is reassuring to observe that all the results resemble straight lines when plotted in semilogarithmic coordinates. This means that Eq. (3) represents an acceptable model to describe the scour evolution in time for all experimental conditions and, more importantly, $\varepsilon$ (which represents the slope of the straight lines) can be taken as an effective parameter to quantify scour severity.

The difference between Figs. 2a (experiments with debris) and 2b (experiments without debris) is striking. It is evident that debris leads to much steeper curves, which ultimately lead to more severe scour. In particular, the comparison between the experimental data with and without debris accumulation reported in Fig. 2c reveals an average increase of the local scour depth of $50 \%$ [based on the so-called debris effect parameter $K_{d}=\varepsilon / \varepsilon_{n d}$ (Table S1, supplemental Appendix I), where $\varepsilon_{n d}$ is the scour evolution rate without debris] and a maximum of $100 \%$ (Tests T03 and T06), approximately. These results contrast with former studies where the dimensions of debris accumulations were assumed a priori and not linked to the appropriate value of $\mathrm{Fr}_{L}$. Such studies reported that debris jams increase the depth of scour by a factor of up to 1.5 to 3.0 times the scour depth observed without accumulation (Melville and Dongol 1992; Pagliara and Carnacina 2010b). This aspect is further discussed and clarified in section "size effects" of the supplemental material where results from the second set of experiments are presented and commented.

Values of $\varepsilon$ in Eq. (3) were determined by linear regression for each experiment using the monitored scour depths in semi-log-form as presented in Fig. 2 (Table 1). A multivariable nonlinear regression was then performed to determine a relation between the dependent parameter $\varepsilon$ and three non-dimensional groups, namely $U^{*}, H / h$ and $A^{*}$, which are assumed to be the most influential on $\varepsilon$ (Pagliara and Carnaciana 2010b). The analysis of the data in Fig. 3a led to the following power law relation 


$$
\varepsilon=\alpha U^{* \beta}\left(\frac{H}{h}\right)^{\chi} A^{* \delta},
$$

168

169

170

171

172

173

174

175

176

177

178

179

180

181

182

183

184

185

186

187

188

189

190

191

192

193

194

where $\alpha=1.72, \beta=1.31, \chi=0.65, \delta=0.13$ and led to the best coefficient of determination after linearization $\left(R^{2}=0.78\right.$ in Fig. 3a). The interdependency between $H / h$ and $A^{*}$ is analyzed in the supplemental Appendix II.

Due to length restrictions, the analyses of the size and permeability effects are available online as supplemental material in the supplemental Appendix III. From Fig. S3 (supplemental Appendix III), it can be drawn that a precise representation of the debris geometry under given flow conditions is important for an accurate assessment of the local scour, which is in line with the findings by Lagasse et al. (2010). Further, from Fig. S4 (supplemental Appendix III), it is suggested that the permeability effect much smaller than the effect of the accumulation itself to a value $\sim 10 \%$.

\section{Discussion and Conclusions}

Eq. (4), which relates the scour evolution rate to the debris geometry and flow conditions, can be found of high practical importance for the risk assessment and design of bridge piers subject to the potential accumulation of woody debris. Since Eq. (3) is differentiable, $\mathrm{d} d_{s} / \mathrm{d} t$ can be integrated using the results from hydraulic simulations providing values of $U(t)$ and $h(t)$ to be used in Eq. (4) and, therefore, $d_{s}(\mathrm{t})$ can be obtained from any initial condition (e.g. pre-event depth of scour). The combination of this approach with the method proposed here to determine the effects of debris on scour (which are based on the actual potential size of accumulations that can be formed under particular conditions and not arbitrarily defined) will lead to a more accurate assessment of scour and therefore cost-effective design.

The accuracy of the results derived from the methods proposed in this study are subjected, however, to the applicability of Eq. (1). Hence, strictly speaking the results apply to single, circular bridge piers subjected to the formation of half-conical woody debris accumulations within the range of conditions described by Panici and de Almeida (2018). However, new results by Panici and de Almeida (2020) show that the dimensions of accumulations formed at piers of different shape are not substantially influenced by the shape (except for square piers, which 
195

196

197

198

199

200

201

202

203

204

205

206

207

208

209

210

211

212

213

214

215

216

217

218

219

220

221

222

223

results in accumulations that are approximately 15\% wider than those formed at other pier shapes). Therefore, the results presented in this paper may also provide a good approximation of scour when applied to other pier shapes. Also, our analysis has only explored the range of flow conditions achievable by the laboratory facilities, namely, $0.2<H / h<0.59,0.37<U^{*}<0.82$ and $0.10<A^{*}<0.24$ and needs to be extended by exploring a wider range of hydrodynamic and debris conditions, which should involve, also, experiments in the live-bed regime.

In this paper, the woody debris accumulations experimentally tested had shape and dimensions linked to the process of collection of individual floating debris elements under given flow conditions at single, circular piers. The main conclusions are:

- When flow-dependent debris accumulations are tested, the local scour depth was found to be within the range of 1.18-2.19 times the corresponding local scour without accumulations.

- The time evolution of local scour with and without debris followed the model proposed by Oliveto and Hager (2002). This suggests that all the experiments could be considered similar and comparable through the rate of scour parameter $\varepsilon$.

- A multi-variable regression analysis allowed us to identify the influence of flow intensity, blockage area ratio, and depth ratio on the development of local scour with flow-dependent debris accumulation.

- Local scour depth with debris accumulation displays a relatively modest dependency on the debris permeability. An experiment using the extreme condition of zero-permeability debris model resulted in only $10 \%$ increase in scour.

Future research in this line could be focused on aspects not fully explored in this work, e.g., the effect of the dimensionless flow depth or the rate at which the debris accumulation forms relative to the rate at which scour develops.

\section{Acknowledgments}

This research is funded by NERC, grant reference NE/R009015/1. The first author was partly funded by the Spanish Ministry of Science, Innovation and Universities through Programa Juan de la Cierva 2016 (FJCI-2016-28009). The authors would like to thank Dr. Toru Tsuzaki, experimental officer in the Hydraulic laboratory at the University of Southampton, for his 
224 assistance during the time this research was accomplished, as well as Mr. Marco Campriani, 225 MSc student at the Politecnico di Torino, who contributed to the experimental campaigns.

226

227 Data Availability Statement

228 Some or all data, models, or code that support the findings of this study are available from the 229 corresponding author upon reasonable request. List of items:

$230 \quad$ - File with all scour depth measurements per experiment.

231

\section{Supplemental Materials}

233 The following appendixes, table and figures are available online in the ASCE Library 234 (ascelibrary.org) in a unique supplemental appendixes document:

235 - Appendix I: Description of the Experimental Campaign,

236 - Appendix II: Interdependency between relative blockage variables,

237 - Appendix III: Secondary Debris Effects on Local Scour, including the subsections Size $238 \quad$ effects and Permeability effects,

$239 \quad-\quad$ Table S1,

$240-$ Figs. S1-S4.

241

242 References

243 Benn, J. (2013). "Railway bridge failure during flooding in the UK and Ireland." Proc. Inst. Civ. 244 Eng. Forensic Eng., 166(4), 163-170.

245 Bradley, J. B., Richards, D. L., and Bahner, C. D. (2005). "Debris control structures: Evaluation 246 and countermeasures.” U.S. Dept. of Transportation, Federal Highway Administration, Rep. 247 FHWA-IF-04-016, Washington, DC.

248 Dey, S. (2014). Fluvial hydrodynamics: Hydrodynamic and sediment transport phenomena. 249 Springer, Berlin. 
250

251

252

253

254

255

256

257

258

259

260

261

262

263

264

265

266

267

268

269

270

271

272

273

274

275

276

Diehl, T. H. (1997). "Potential drift accumulation at bridges." U.S. Dept. of Transportation, Federal Highway Administration, Rep. FHWA-RD-97-028, Washington, DC.

Lagasse, P. F., Clopper, P. E., Zevenbergen, L. W., Spitz, W. J., and Girard, L. G. (2010). "Effects of debris on bridge pier scour." National Cooperative Highway Research Program (NCHRP) Rep. No. 653, Transportation Research Board, Washington, DC.

Laursen, E. M., and Toch, A. (1956). Scour around bridge piers and abutments, Iowa Highway Research Board, Ames, IA.

Lavy, E. E. (1956). River mechanics, National Energy Press, Moscow.

Melville, B. W., and Coleman, S. E. (2000). Bridge scour, Water Resources Publications, Highlands Ranch, CO.

Melville, B., and Dongol, D. (1992). "Bridge pier scour with debris accumulation.” J. Hydraul. Eng., 10.1061/(ASCE)0733-9429(1992)118:9(1306), 1306-1310.

Najafzadeh, M., Saberi-Movahed, F. and Sarkamaryan, S., (2017). "NF-GMDH-Based selforganized systems to predict bridge pier scour depth under debris flow effects." Mar. Georesour. Geotech., 1-14.

Oliveto, G., and Hager, W. (2002). "Temporal evolution of clear-water pier and abutment scour." J. Hydraul. Eng., 10.1061/(ASCE)0733-9429(2002)128:9(811), 811-820.

Oliveto, G., and Hager, W. (2005). "Further results to time-dependent local scour at bridge elements." J. Hydraul. Eng., 10.1061/(ASCE)0733-9429(2005)131:2(97), 97-105.

Pagliara, S. and Carnacina, I., (2010a). "Influence of wood debris accumulation on bridge pier scour." J. Hydraul. Eng., 10.1061/(ASCE)HY.1943-7900.0000289, 254-261.

Pagliara, S., and Carnacina, I. (2010b). "Temporal scour evolution at bridge piers: Effect of wood debris roughness and porosity." J. Hydraul. Res., 48(1), 3-13.

Pagliara, S., and Carnacina, I. (2011). "Influence of large woody debris on sediment scour at bridge piers." Int. J. Sediment Res., 26(2), 121-136.

Pagliara, S., and Carnacina, I. (2013). "Bridge pier flow field in the presence of debris accumulation." Proc. Inst. Civ. Eng. Water Manag. 187-198. 
277 Pagliara, S., Carnacina, I., and Cigni, F. (2010). "Sills and gabions as countermeasures at bridge 278 pier in presence of debris accumulations.” J. Hydraul. Res., 48(6), 764-774.

279 Panici, D. and de Almeida, G. A. (2017). "Understanding the formation of woody debris jams at bridge piers." Proc. $37^{\text {th }}$ IAHR Congress, Kuala Lumpur, Malaysia.

281 Panici, D. and de Almeida, G. A., (2018). "Formation, growth and failure of debris jams at 282 bridge piers.” Water Resour. Res., 54(9), 6226-6241.

283 Panici, D. and de Almeida, G. A., (2020). "The influence of pier geometry and debris 284 characteristics on the accumulation of woody debris at bridge piers" J. Hydraul. Eng., 285 10.1061/(ASCE)HY.1943-7900.0001757, 04020041.

286 Parola, A. C., Apeldt, C. J., and Jempson, M. A. (2000). "Debris forces on highway bridges." 287 National Cooperative Highway Research Program (NCHRP) Rep. No. 445, Transportation 288 Research Board, National Research Council, Washington, DC.

289 Rahimi, E., Qaderi, K., Rahimpour, M., and Ahmadi, M. M. (2017). "Effect of debris on piers 290 group scour: An experimental study.” KSCE J. Civ. Eng., 1-10.

291 Schmocker, L., and Hager, W.H. (2013). "Scale modelling of wooden debris accumulation at a 292 debris rack.” J. Hydraul. Eng., 10.1061/(ASCE)HY.1943-7900.0000714, 827-836. 
1 Table 1. Scour experiments results

\begin{tabular}{cccccc}
\hline Tests & $U_{c}$ & $U / U_{c}$ & $\varepsilon$ & $\varepsilon_{n d}$ & $K_{d}$ \\
\hline T01 & 0.6 & 0.48 & 0.12 & 0.085 & 1.41 \\
T02 & 0.61 & 0.63 & 0.27 & 0.16 & 1.69 \\
T03 & 0.58 & 0.86 & 0.73 & 0.36 & 2.03 \\
T04 & 0.59 & 0.57 & 0.29 & 0.18 & 1.61 \\
T05 & 0.51 & 0.37 & 0.09 & 0.045 & 2.00 \\
T06 & 0.54 & 0.44 & 0.285 & 0.13 & 2.19 \\
T07 & 0.57 & 0.5 & 0.245 & 0.15 & 1.63 \\
T08 & 0.62 & 0.53 & 0.2 & 0.17 & 1.18 \\
T09 & 0.62 & 0.59 & 0.34 & 0.24 & 1.42 \\
T10 & 0.6 & 0.62 & 0.34 & 0.24 & 1.43 \\
T11 & 0.54 & 0.68 & 0.48 & 0.335 & 1.39 \\
T12 & 0.6 & 0.68 & 0.32 & 0.23 & 1.18 \\
T13 & 0.55 & 0.52 & 0.385 & 0.27 & 1.43 \\
T14 & 0.57 & 0.59 & 0.52 & 0.355 & 1.46 \\
T15 & 0.59 & 0.65 & 0.57 & 0.39 & 1.46 \\
T16 & 0.57 & 0.65 & 0.49 & 0.37 & 1.32 \\
T17 & 0.55 & 0.69 & 0.39 & 0.25 & 1.56 \\
\hline
\end{tabular}

2 Note: $U_{c}$ is computed following the mean critical velocity method as proposed by Lavy (1956). 
(a)

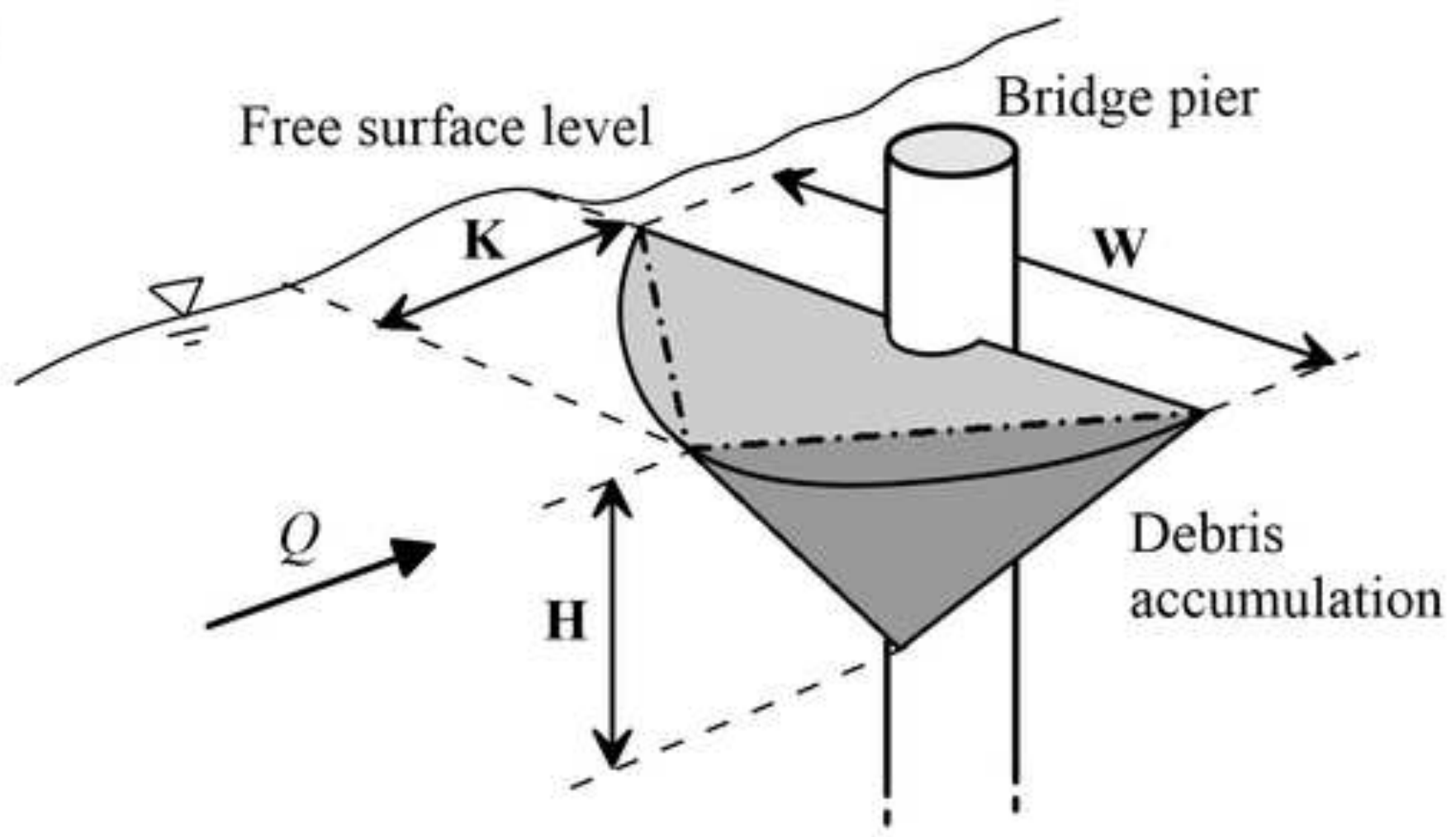

(b)

Bridge pier

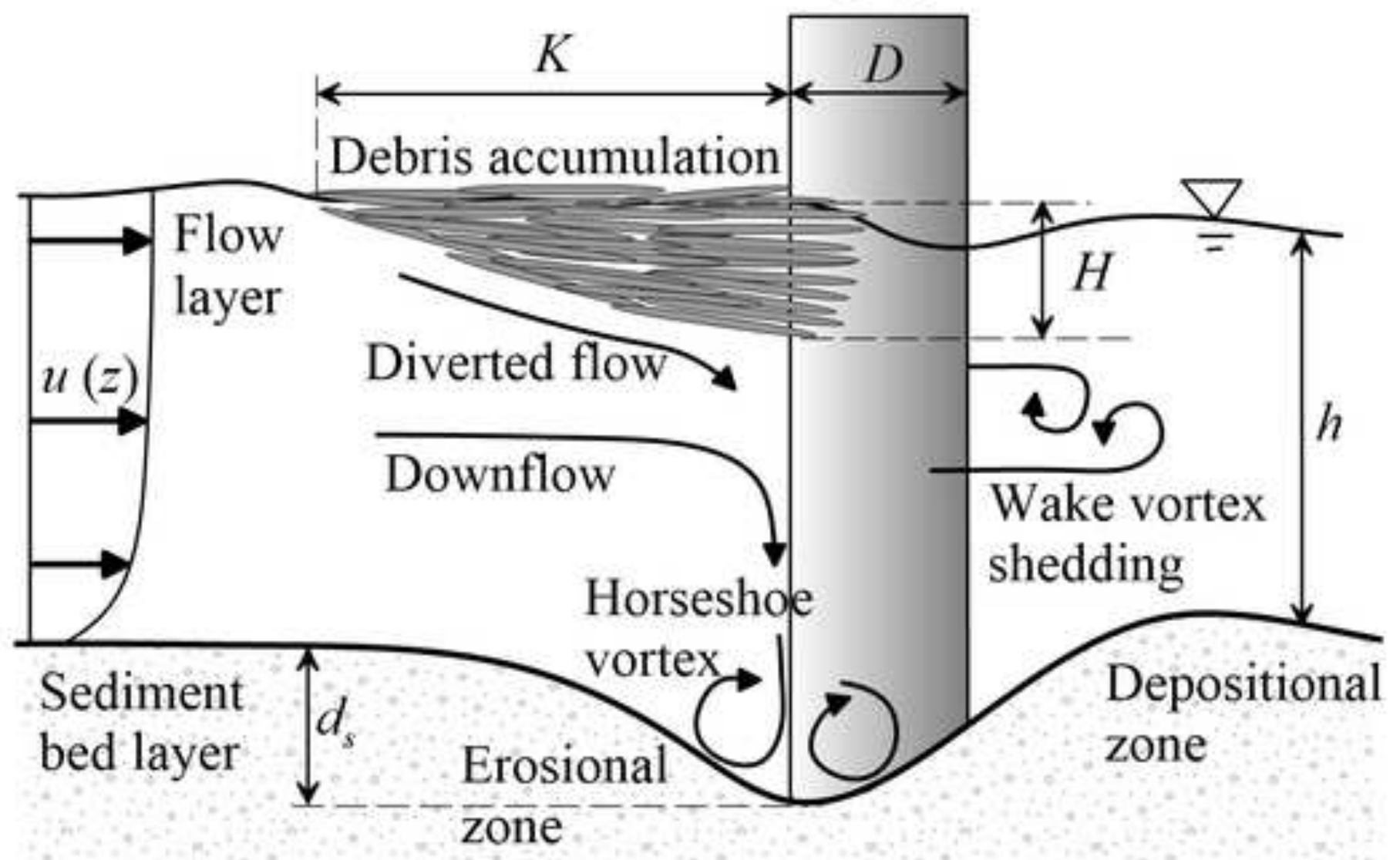

Scour hole 


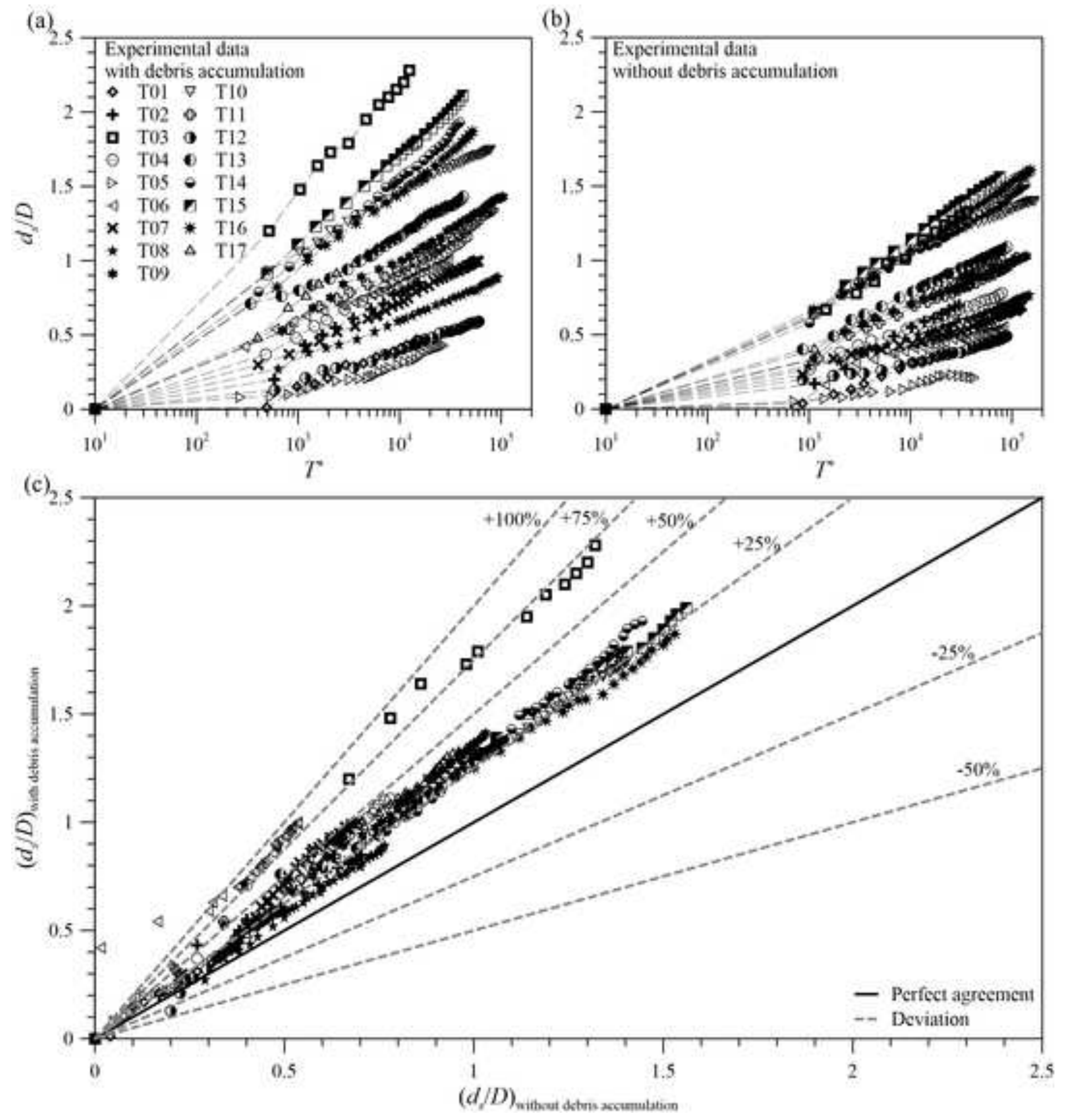

(b) 
Click here to access/download;Figure;Fig3.tif $\underline{\underline{\Perp}}$

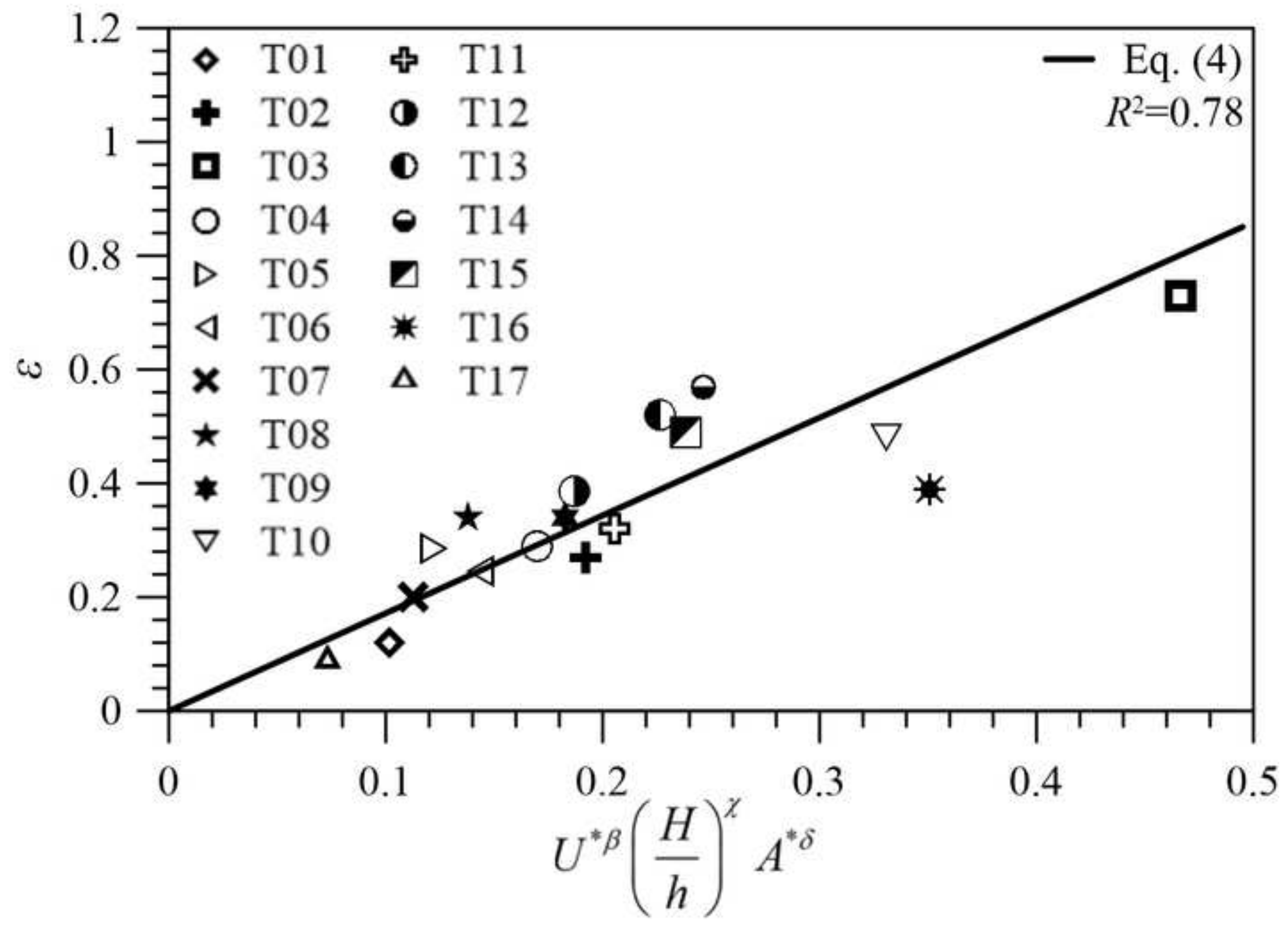




\section{Figure Captions List}

2

3 Fig. 1. Definition sketches of a permeable woody debris accumulation at the front of a bridge 4 pier in a river flow of discharge $Q$ : (a) perspective and (b) lateral view

5 Fig. 2. Non-dimensional scour evolution data for tests T01-T17 being: (a) with debris 6 accumulation; and (b) without debris accumulation. (c) comparison between the local scour 7 depth data of tests T01-T17 with and without debris accumulation with deviation lines for $\pm 25 \%$, $8 \pm 50 \%,+75 \%$, and $+100 \%$

9 Fig. 3. Power regression for experimental $\varepsilon$-data with debris accumulation for tests T01-T17 by 10 Eq. (4) 